DE DE GRUYTER OPEN
Research Article

(c) 2018 Bouziane Athmen and Belhadef Samia. This is an open access article licensed under the Creative Commons Attribution-NonCommercial-NoDerivs License (http://creativecommons.org/licenses/by-nc-nd/3.0/).

\title{
The Importance of Human Resources in Corporate Governance
}

\section{Bouziane Athmen}

\author{
Professor at Dr. Moulay Tahar University of Saida, Algeria
}

\section{Belhadef Samia}

\author{
Student of Doctoral Economics, Corporate Governance Program,
} Dr. Moulay Tahar University of Saida, Algeria

Doi: $10.2478 / m j s s-2018-0086$

\begin{abstract}
The purpose of this research is to clarify the status of human resources in terms of corporate governance through chart analyses. These analyses are based on theoretical principles that clarify the relationship between human resources and corporate governance, and they are divided based on two perspectives. The first one is the corporate governance perspective, and the second is that of the human resources, whereas the administrative board is considered as a common point between them. Human resources is one the most important points that must be addressed by corporate governance. The literature review of this study includes the theories and models of corporate governance, such as the Agency Theory, and the Theory of Stakeholders, and Shareholders Model. As for the literary sources for the study of human resources, they include articles specialized in the study of corporate governance and human resources to analyze the relationship between them based on a series of methodological steps including the literature review and the collection of relevant data from primary and secondary sources.
\end{abstract}

Keywords: Human resources, corporate governance, board of directors, social responsibility, Stakeholder

\section{Introduction}

Corporate governance is a means that leads to the improve the productivity of companies from a critical viewpoint to prevent them from falling into crisis because of the weak management that can worsen the financial and administrative corruption. More precisely, corporate governance appeared as a new method of management based on a set of principles and procedures that govern the administration on one hand, and the parties of the deals on the other hand.

All of this is for the sake of giving the shareholders their due importance in order to maximize their confidence in the members of the administrative board through reliance on constant control, auditing and the risk management.

It has been noticed from the previous studies that investigate the subject of corporate governance that many of them were limited to the financial side (accounting disclosure, financial performance, increasing the capital of the companies) at the expense of the human side (HR, labour, the human resources performance). It is known, however, that the basics of the theory and the models of corporate governance are all based on human resources as the most important party of the deal and the most important target of corporate governance. Human resources urge the commitment to the ethics and values of the job to create the organizational value, since that can only be achieved through the factors of training, motivation, job satisfaction and participation. 


\section{Research Methodology}

The research adopts a multi-methodology approach based mainly on descriptive and analytical research methodologies, since it sets to define and describe the basics to determine their argumentative and problematic points, and then analyzes these problems to produce solutions based on the human resources. The research opts to describe first the different theoretical postulations and their arguments, to find out the results of their applications by analyzing them in correlation in a comparative way to find out the importance of the role of human resources. The comparative and correlational descriptive research paradigm helps find out which factors are most essential, without intervention and without modifying the variables.

The analytical research paradigm, on the other hand, is useful since the research is based on the theories mentioned above. Basic research exists already and the researcher sets to analyze the theoretical information in order evaluate these theories and provide an elaborate explanation of the relationship between corporate governance and human resources from a new perspective based on a different methodology. The researchers analyze the vital function of human resources in corporate governance to highlight its other functions on different levels, especially the sociological level, since most previous studies highlight mainly the financial level. The analytical research methodology is then vital when approaching a certain analysis through different theories, especially for evaluation.

\section{Results and Discussion}

\subsection{The Relationship of Human Resources and Corporate Governance}

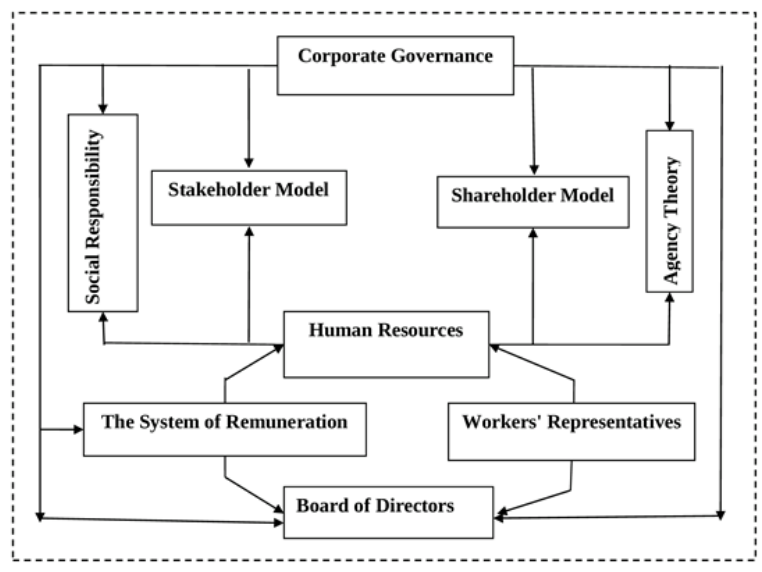

Figure 1: The Relationship of Human Resources and Corporate Governance

The diagram shown above indicates a clarification of the importance of human resources in the corporate governance, and that is divided into two parts:

\subsection{The Importance of Human Resources in the Corporate Governance from the Perspective of Corporate Governance:}

In this perspective, this position is clarified through the examples of corporate governance. They are divided into two main categories based on defining the relationship between them. For the first model (Shareholder) for example, this relationship is limited to one important representative of human resources, who is the Executive Director (Manager) with the shareholders. This limited relationship caused issues that led to the necessity to the separate between the management and 
the ownership (Consider Berle and Means, 1932), the fact which led to the emergence of the agency problem (See Jensen and Meckling 1976). The relationship was limited only to the Executive Director, it is inferred from him that the model neglecting the other side of human resources, which is the dynamic element in the company, in the precise sense, not granted to employee in company status, where their role was confined to the performance of the specific job, without granting them the privileges that would achieve the strategically goals of the company.

Finally, we can say that the position of human resources in corporate governance under the Shareholder Model is partial since its most important role has been marginalized. This has led to the necessity to create a new model that can upgrade the position of human resources in order to realize the qualification and efficiency to guarantee the highest levels of performance. This new model in known as the Stakeholder Model, which was defined by Milton Freedman.

According to Freeman (1984), stakeholders are individuals or groups who can affect or be affected by the purposes and business success; however, several scholars have suggested that this definition is too broad, because in the final analysis all social players are directly or indirectly affected by the actions of the company. What has given rise to different classifications of stakeholders, has suggested that they are primary and secondary, according to the degree of impact on the organization in terms of achieving its mission and objectives of the company. (Donaldson \& Preston, 1995; Freeman, 1984).

The general idea of the Stakeholder concept is a redefinition of the organization. In general the concept is about what the organization should be and how it should be conceptualized. Freedman (2006) states that the organization itself should be thought of as grouping of stakeholders and the purpose of the organization should be to manage their interests, needs and viewpoints. This stakeholder management is thought to be fulfilled by the managers of a firm. The managers should on the one hand manage the corporation for the benefit of its stakeholders in order to ensure their rights and the participation in decision making and on the other hand the management must act as the stockholder's agent to ensure the survival of the firm to safeguard the long term stakes of each group. (Fontaine and Haarman and Schmid, 2006).

Milton Freedman considered the employee as one of the most important factors that influence and affects the enterprise. This indicates that the fact a company that follows the corporate governance would also affect human resources and be affected by it. This leads to the creation of the value and realization of job satisfaction and commitment, and by that, it would have already social responsibility, which generally aims to ensure the rights of individuals within the company, by considering them before all as customers enrolling in it.

\subsection{Human Resources Position in Corporate Governance from the Perspective of Human Resources}

It is clear that human resources has a vital position in corporate governance because it is believed to be the basic pillar when properly applied. Human resources is considered as the mediator in all dealings, and even when applying different labels, (workforce, employees, workers, administrative agents, executive director...etc.), the purpose does not change; it remains the "human resources purpose". Amongst the interests of this field is that the employee takes part in corporate governance, which is the main point that was clarified by Michael LP Lower (2009).

Employee participation can also refer to decision-making at levels below the board such as the workplace or within the employee's immediate 'team'. This participation might be direct with each individual employee participating in the decision-making process. More usually, however, it will be indirect in that employees participate in governance through representatives. (Lower, 2009).

The participation of the employee in the corporate governance is a clear indication of the position of human resources. It is sought mainly through increasing the productivity that results from the psychological comfort of staff, the fact which leads to increase the level of all various kinds of creativity, especially the administrative innovation and managerial leadership. The latters can reduce the agency problem and the contradictory interests, in order to rise up to the highest levels of performance (financial, organizational, and human) that insure the rights of all stakeholders. Konzelmann et al. (2006) relate to the present research as being the most important 
source that has linked between corporate governance and human resources, and being the one who provided an important addition in this area, especially in clarifying that the interrelationship between the two sectors is a direct one. They also stated that the central purpose of HRM is enhancing performance and in turn HRM itself, is affected by the implementation of corporate governance practices. Therefore, the demands of the stakeholder could influence. on the HRM practices developed and implemented. (Konzelmann et al, 2006).

The diagram explains how the administrative board is considered as the main engine, or the common point between corporate governance and human resources. The use of the remuneration and compensation systems, which give privileges to the Executive Director to be a shareholder in the company, and increase the motivation of "wage earners", are amongst the corporate governance duties, which consider the administrative board as one of its internal mechanisms that guarantee applying it properly. On the other side, the human resources in the administrative board occur in the presence of the Executive Director and the workers' representative and the internal auditor. The latter works on the proper and accurate disclosure of information under the framework of transparency in order to lay the strategic plan that makes the foundation pillar of the company on behalf of the investors. All of this comes in order to improve the ability of companies to create the added value.

\section{Conclusion}

Corporate governance is one of the most important topics in strategic management research and practice. That is why we cannot speak about the proper application of the rules and principles of corporate governance without talking about the human resources, which is one of the foundations to achieve the planned objectives. We must take into account of consideration the human resources within an organization, which comprises both the Executive Director and workers and considers them as a portion of the sets through which a company would aim to increase investments to achieve the added values. This demonstrates that the relationship between human resources and corporate governance is a complementary one because each element affects and is affected by the second element.

Corporate governance affects human resources through several factors, the most important of which is the systems of remuneration and compensation that contribute to create the added value and to realize the professional satisfaction. This interest also realizes one of the very important aspects of social responsibility, which has become recently one of the criteria of competitiveness, which is improved when the administrative board is well managed to properly exert its responsibilities and make the best strategic decisions through the consultation with its human resources. This can realize the achievement of better performance and increased productivity that lead to the increase in profits, which means realizing advantages for all interested parties, including stakeholders and shareholders.

\section{References}

Berle, A. \& Means, G. (1932). The Modern Corporation and Private Property. New York: Macmillan.

Donaldson, T. \& Preston, L.E. 1995. The stakeholder theory of the corporation: Concepts, Evidence and implications. Academy of Management Review, 20: 65-91.

Fontaine, C \& Haarman, A \& Schmid, S (2006). The Stakeholder Theory, stakeholder Theory of the MNC. December.

Freeman, R. E. 1984. Strategic management: A stakeholder approach. Boston: Pitman.

Jensen, M. C \& Meckling, W. H. 1976. Theory of the firm: Managerial behaviour, agency Costs and ownership structure. Journal of Financial Economics, 3: 305-360.

Konzelmann, S \& Conway, N \& Trenberth, L \& Wilkinson, F. 2006. Corporate governance And Human Resource Management. British Journal of Industrial Relations, 44: 541567.

Lower. M "Employee participation in corporate governance: an ethical analysis" (2009) Available at: http://works.bepress.com/michael_lower/5/.p1 